\title{
Perencanaan Strategis Sistem Informasi Menggunakan Website Sabagai Sarana Penjualan Global Di Produk Qly's Eyelashes
}

\author{
Kristian Mei Handoko ${ }^{1}$, Agustinus Fritz Wijaya ${ }^{2}$ \\ 1,2Information System, Fakultas Teknologi Informasi, Satya Wacana Christian University, \\ Indonesia \\ E-mail:1682017015@student.uksw.edu_2 Agustinus.wijaya@uksw.edu
}

\begin{abstract}
In this era of globalization, many people use websites as their sales ground. Because it is considered to be able to cover a wider range of sales and if a product already has a web, it will be more trusted and will be more popular in the market, because potential consumers in the present era if they want to buy a product will look for it on the internet first. Is this product famous or not, is this product trusted or not and so on. Furthermore, if people who have products but do not have a website or do not display their products on other websites or social media, then it is certain that these products will be less competitive and not sell well in the market. In this context, I as a researcher want to use Ward and Peppard analysis and SWOT analysis.
\end{abstract}

Keywords: Information Systems Strategic Planning, Websites and social media, Ward and Peppard, SWOT analysis.

\section{PENDAHULUAN}

Pada era modern seperti sekarang masyarakat sudah mulai banyak yang meninggalkan proses jual beli melalui tatap muka. Sekarang masyarakat Indonesia dan dunia sudah mulai menggunakan website sebagai sarana jual beli karena dinilai lebih efisien untuk pembeli dan memudahkan penjualan bagi penjual. Maka dari itu dibuatlah Perencanaan strategis SI/TI untuk mnganalisis bisnis internal dan menentukan strategi SI/TI pada penjualan bulu mata QLY'S Eyelashes supaya lebih menguntungkan lagi untuk masa mendatangnya.

QLY'S Eyelashes sendiri adalah suatu produk kecantikan yang berfokus pada produksi dan penjualan bulumata. Dalam proses jual beli biasanya owner QLY'S Eyelashes menggunakan cara transaksi yang masih tradisional, yaitu dengan bertatap muka yaitu dengan cara mereka menawarkan barang dari toko ke 


\section{Journal of Software Engineering Ampera}

Vol. 1, No. 3, October 2020 e-ISSN: 2775-2488

https://journal-computing.org/index.php/journal-sea/index

toko, Selanjutnya mereka menawarkan pesannanya lagi ke toko yang sudah pernah ditawarkan melalui WHATSAPP chat supaya pembeli membeli produk mereka lagi. Di beberapa bulan terkahir ini sejak pandemi mereka mulai membuat strategi bisnis baru, yaitu dengan menggunakan strategi bisnis sistem informasi guna menyesuaikan dan mengikuti perkembangan bisnis. QLY'S sendiri membuat strategi bisnis dengan membuat toko online di bebrapa platform penjualan terkenal seperti bukalapak, shopee guna menawarkan hasil produk-produk bulu mata mereka. Dalam hal ini saya menyimpulkan mereka sudah mempunyai dan menggunakan sistem informasi tetapi masih sangat sederhana karena hanya mengandalkan Whatsapp, Bukalapak, dan Shopee.

QLY'S Eyelashes sendiri berlokasi di kota Purbalingga, Jawa Tengah. Saat ini target penjualan mereka hanya tertuju langsung ke toko-toko dan perias(MUA). Untuk mengatasi kalah bersaing penjualan dengan produk bulumata yang lainnya sangat dibutuhkan sekali perencanaan strategi bisnis Penjualan. Disini peneliti menggunakan analisa SWOT untuk menilai bagaimana proses penjualan saat ini, apakah penjualan saat ini sudah efektif atau belum, Bagaimana peluang pasar bulumata QLYS dikemudian hari, dan bagaimana QLYS dapat menembus pasar global .

\section{METODE}

Dalam penelitian ini peneliti menggunakan metode penelitian deskriptif kualitatif. Disebut penelitian deskriptif karena dalam penelitian ini saya terjun langsung dan menganalisa kegiatan-kegiatan bisnis yang dilakukan disana. Menurut Menurut Sugiyono menyatakan bahwa metode deskriptif adalah suatu metode yang digunakan untuk menggambarkan atau menganalisis suatu hasil penelitian tetapi tidak digunakan untuk membuat kesimpulan yang lebih luas. Sedangkan menurut Nazir dalam Buku Contoh Metode Penelitian, metode deskriptif merupakan suatu metode dalam meneliti status sekelompok manusia, suatu objek, suatu set kondisi, suatu sistem pemikiran ataupun suatu kelas peristiwa pada masa sekarang. Tujuan dari penelitian deskriptif ini adalah untuk membuat deskripsi, gambaran, atau lukisan secara sistematis, faktual dan akurat mengenai fakta-fakta, sifat-sifat serta hubungan antar fenomena yang diselidiki. Sedangkan menurut Whitney metode deskriptif adalah pencarian fakta dengan interpretasi yang tepat. (Nazir, 2016).

Disebut penelitian kualitatif karena dalam pengumpulan data ini saya menggunakan metode wawancara dan memantau lapangan langsung dengan 


\section{Journal of Software Engineering Ampera}

Vol. 1, No. 3, October 2020 e-ISSN: 2775-2488

https://journal-computing.org/index.php/journal-sea/index

owner QLYS Eyelashes langsung. Menurut Sugiyono, metode penelitian kualitatif adalah metode penelitian yang berlandaskan pada filsafat post positivisme, digunakan untuk meneliti pada kondisi obyek yang alamiah, (sebagai lawannya eksperimen) dimana peneliti adalah sebagai instrumen kunci, pengambilan sampel sumber data dilakukan secara purposive dan snowball, teknik pengumpulan dengan tri-anggulasi (gabungan), analisis data bersifat induktif atau kualitatif, dan hasil penelitian kualitatif lebih menekankan makna dari pada generalisasi, sedangkan Menurut Saryono, Penelitian kualitatif merupakan penelitian yang digunakan untuk menyelidiki, menemukan, menggambarkan, dan menjelaskan kualitas atau keistimewaan dari pengaruh sosial yang tidak dapat dijelaskan, diukur atau digambarkan melalui pendekatan kuantitatif.

Karena dalam penelitian ini, peneliti langsung secara langsung mewawancarai narasumber. Maka untuk melakukan wawancara perlu dibuat tahapan terlebih dahulu, berikut tahapan-tahapannya:

a) Menentukan tema yang akan ditanyakan kepada narasumber.

b) Membuat jadwal kapan akan wawancara.

c) Menyusun pertanyaan wawancara.

d) Melakukan wawancara dengan narasumber.

e) Mencatat percakapan dengan narasumber.

Lalu setelah menggunakan metode deskriptif kualitatif peneliti juga menggunakan metode Ward and Peppard untuk menganalisa rencana bisnis, selanjutnya menggunakan analisa SWOT untuk memetakan kerentanan bisnis di QLY'S Eyelashes.

Dalam metode Ward and Peppard sudah banyak yang menggunakan metode ini untuk menganalisa portofolio bisnis perusahaan. Contoh penelitian yang pernah menggunakan metode Ward and Peppard ini yaitu "Perencanaan Strategis Sistem Informasi dengan Pendekatan Ward and Peppard Model (Studi Kasus: Klinik INTI Garut)". Pada penelitian ini peneliti bertujuan untuk menganalisa apakah di INTI Garut ini sudah layak dan sudah bisa bersaing dengan bidang kesehatan lainnya atau belum, merancang perencanaan strategi sistem informasi untuk mendukung bisnis di INTI Garut. (Sujana, 2017)

Selain itu penelitian lainnya yaitu yang berjudul "Perencanaan Strategis SI/TI dengan Menggunakan Framework Ward and Peppard di Sekolah Tinggi IImu Kesehatan (Stikes) Hang Tuah Pekanbaru". Di judul ini peneliti mempunyai satu rumusan masalah yang utama, yaitu bagaimana menciptakan perencanaan 


\section{Journal of Software Engineering Ampera}

Vol. 1, No. 3, October 2020 e-ISSN: 2775-2488

https://journal-computing.org/index.php/journal-sea/index

strategis SI/TI yang baik yang dapat diterapkan pada STIKes Hang Tuah Pekanbaru. Peneliti berkesimpulan jika di STIkes Hang Tuah Pekanbaru dihasilkan beberapa perencanaan Strategis SI/TI yang berupa perencanaan strategi SI, perencanaan strategi $\mathrm{TI}$, dan perencanaan strategi manajemen SI/TI berdasarkan analisis lingkungan Internal dan Eksternal bisnis, serta analisis lingkungan Internal dan Eksternal SI/TI. (Irawan, 2017)

Perencanaan strategis Sistem Informasil/Teknologi Informasi dalam sebuah organisasi merupakan proses yang berkelanjutan yang akan perlu sering diperbarui secara teratur sebagai respon terhadap dorongan eksternal, peluang dan kebutuhan bisnis, rencana kerja yang terjadwal, budaya organisasi dan kemanfaatan yang diperoleh dari penerapan strategi itu sendiri. Perbaruan itu bisa berupa revisi yang relatif kecil namun tidak tertutup kemungkinan dibutuhkan perubahan mendasar dan menyeluruh, bergantung pada keluasan cakupan proses strategis organisasi (Wijaya, 2017) .

Adapun beberapa jenis model Perencanaan Strategi Sistem Informasi, diantaranya :

a) Lingkungan bisnis internal organisasi, Merupakan strategi bisnis yang digunakan pada masa sekarang, tujuan, sumberdaya, proses dan budaya organisasi serta nilai dari bisnis itu sendiri.

b) Lingkungan bisnis eksternal organisasi, Pada tahap ini dilakuakan analisis faktor-faktor di luar organisasi yangmempengaruhi kinerja organisasi, yang mencakup aspek-aspek ekonomi, industri,dan iklim bersaing perusahaan.

c) Lingkungan internal SI/TI, Pada tahap ini akan dilakukan analisis yang mencakup kondisi SI/TI organisasidari perpektif bisnis saat ini bagaimana kematangannya (maturity), bagaimana kontribusi terhadap bisnis, keterampilan sumber daya manusia, sumber daya dan infrastruktur teknologi, termasuk juga bagaimana portofolio dari $\mathrm{SI} / \mathrm{TI}$ yang ada saat ini.

d) Lingkungan eksternal SI/TI, Pada tahap ini dilakukan analisis kondisi teknologi SI/TI yang berkembang saatini yang mencakup tren teknologi dan peluang pemanfaatannya, serta penggunaanSI/TI oleh kompetitor, pelanggan dan pemasok. Dari hasil ini akan diperoleh peluang teknologi $\mathrm{SI} / \mathrm{TI}$ yang dapat digunakan dalam mendukung strategi organisasi. 


\section{Journal of Software Engineering Ampera}

Vol. 1, No. 3, October 2020 e-ISSN: 2775-2488

https://journal-computing.org/index.php/journal-sea/index

Kotler dan Armstrong dalam Adhagassani mendefinisikan bahwa marketing mix adalah perangkat alat pemasaran taktis yang dapat dikendalikan, produk, harga, promosi dan distribusi yang dipadukan oleh perusahaan untuk menghasilkan respon pasar yang diinginkan. Marketing mix adalah variabelvariabel yang dipakai oleh perusahaan sebagai sarana untuk memenuhi atau melayani kebutuhan dan keinginan konsumen. Adhaghassani menyatakan marketing mix adalah kombinasi variabel atau kegiatan yang merupakan inti dari sistem pemasaran, variabel mana dapat dikendalikan oleh pemasaran untuk mempengaruhi reaksi para pembeli atau konsumen (Adhaghassani, 2016). Dari definisi di atas dapat diartikan bahwa bauran pemasaran merupakan variable-variabel terkendali yang digabungkan untuk menghasilkan tanggapan yang diharapkan dari pasar sasaran. Dan untuk usaha jasa terdapat 7 unsur marketing mix (Marketing Mix-7p) yaitu: Produk, Harga, Promosi, Proses, Lingkungan fisik, Tempat.

a) Produk, Produk adalah sesuatu yang kita akan jual kepada konsumen. Saat akan membuat produk ada baiknya kita meriset terlebih dahulu untuk mengetahui kebutuhan pasar.

b) -Harga, Menurut Monroe (2005) menyatakan bahwa harga merupakan pengorbanan ekonomis yang dilakukan pelanggan untuk memperoleh produk atau jasa. Selain itu harga salah satu faktor penting konsumen dalam mengambil keputusan untuk melakukan transaksi atau tidak. Sehingga disini diharapkan pemilik produk membuat harga yang relatif murah dibanding kompetitor yang serupa agar lebih banyak dilihat orang terlebih dahulu.

c) -Tempat, Yang dimaksud dalam tempat adalah tempat untuk menjual produk barang(offline). perusahaan juga harus meriset terlebih dahulu dimana biasanya target pasar berkumpul, lalu perusahaan membuat store.

d) -Promosi, Promosi adalah kegiatan untuk memberi tau kepada orangorang bahwa kita mempunyai dan menjual produk ini. Kita menjelaskan dengan baik dan detail mengenai produk kita di promosi itu kepada konsumen bisa melalui

e) Periklanan, koran, majalah, instagram, dan lain-lain.

f) -Sumber daya manusia, Sumber daya manusia disini adalah orang-orang yang nantinya akan membuat produk ini. Apakah memenuhi syarat untuk masuk sebagai karyawan atau tidak.

g) -Proses, Yang dimaksud dari proses adalah transaksi antara perusahaan dan pelanggan. Penting juga agar perusahaan membuat pelanggan tetap percaya terhadap perusahaan sampai barang diterima. Dan perusahaan juga harus membuat survei agar perusahaan bisa mengevaluasi. 


\section{Journal of Software Engineering Ampera}

Vol. 1, No. 3, October 2020 e-ISSN: 2775-2488

https://journal-computing.org/index.php/journal-sea/index

h) -Lingkungan fisik, Lingkungan fisik adalah keadaan atau kondisi yang bisa dilihat dan dirasakan oleh konsumen, misal dalam konteks bulumata, konsumen bisa melihat contoh bulumata yang akan ditawarkan juga.

\section{HASIL DAN PEMBAHASAN}

QLY'S Eyelashes merupakan produk kecantikan yang berfokus pada pembuatan bulumata. QLY'S Eyelashes berlokasi di kota Purbalingga, Jawa Tengah. QLY'S Eyelashes didirikan pada tahun 2013. saat ini penjualan bulumata QLYS ini biasanya dipasarkan di Jawa Tenga, Jawa Barat, Jakarta, Bali, dll. QLYS sendiri biasanya menjual produk dengan packaging dan tidak packaging(tergantung pada permintaan pelanggannya). Baru-baru ini QLYS mulai melakukan ekspor ke 2 negara yaitu amerika dan turki. QLYS sendiri sudah menggunakan sistem informasi tetapi belum terstruktur.

Menurut Pearce dan Robinson, pengertian analisis SWOT adalah bagian dari prosesmanajemen strategik perusahaan yang bertujuan untuk mengidentifikasi kekuatan dan kelemahan utama perusahaan. Kelemahan dan kekuatan utama tersebut dibandingkan dengan peluang dan ancaman ekstern sebagai landasan untuk menghasilkan berbagai alternatif strategi.

Disini akan dipetakan berdasarkan analisis SWOT yang terdapat di QLYS Eyelashes:

\section{A. Strength}

- Merk bulumata QLY'S sudah mulai terkenal di kota-kota besar.

- Sudah banyak pelanggan yang percaya pada produk QLYS.

- Bulumata QLY'S mempunyai banyak varian model.

- Selalu mengikuti tren.

B. Weakness

- Masih kurang dalam hal promosinya.

C. Opportunities

- Penduduk wanita di Indonesia sangat banyak sehingga sangat meyakinkan untuk berjualan produk bulumata .

- Trend bulumata di kalangan wanita sedang naik daun.

D. Threats

- Banyaknya pesaing produk bulumata. 


\section{Journal of Software Engineering Ampera}

Vol. 1, No. 3, October 2020 e-ISSN: 2775-2488

https://journal-computing.org/index.php/journal-sea/index

- Adanya pandemi sehingga menurunya permintaan bulumata.

Analisis Value Chain di QLYS terlihat di gambar di bawah ini

\begin{tabular}{|l|l|l|l|l|}
\hline $\begin{array}{l}\text { Aktivitas } \\
\text { Utama }\end{array}$ & Penjualan & Promosi & Produksi & \\
\hline $\begin{array}{l}\text { Aktivitas } \\
\text { Pendukung }\end{array}$ & $\begin{array}{l}\text { Manajemen } \\
\text { SDM }\end{array}$ & $\begin{array}{l}\text { Mempersiapkan } \\
\text { bahan baku }\end{array}$ & Pembukuan & $\begin{array}{l}\text { Perekrutan } \\
\text { Pegawai }\end{array}$ \\
\hline
\end{tabular}

Gambar 1. Analisa Value Chain Activity

Di dalam promosi penjualan atau melakukan aktifitas yang lainnya di QLY'S Eyelashes sudah menggunakan sistem informasi, tetapi masi belum terstruktur dan masih ala kadarnya. Berikut akan dipaparkan apa aja yang dipakai dalam melakukan aktivitas di QLYS Eyelashes:

\begin{tabular}{|l|l|}
\hline SI PROMOSI & Menggunakan Whatsapp \\
\hline SI PENJUALAN & $\begin{array}{l}\text { Masih Berkeliling dan menggunakan } \\
\text { Whatsapp }\end{array}$ \\
\hline PEREKRUTAN PEGAWAI & Menggunakan Platform Facebook \\
\hline
\end{tabular}

Gambar 2. McFarlan Strategic Grid Portofolio

Rekomendasi yang cocok untuk meningkatkan strategi bisnis di QLYS Eyelashes adalah: Mengupgrade pada bagian promosinya dengan menggunakan media sosial, dan website untuk memajang produk-produk. Mengupgrade pada bagian penjualan dengan membuat website penjualan

\section{KESIMPULAN}

Berdasarkan penelitian yang sudah diteliti, di QLY'S Eyelashes terdapat beberapa aktivitas utama dan aktivitas pendukung. QLY'S Eyelashes sendiri sudah menggunakan sistem informasi, tetapi masih sangat sederhana dan apa adanya, seperti menggunakan Whatsapp saja untuk melakukan promosi dan penjuualannya. Disini saya merekomendasikan untuk dibagian promosi dan penjualannya. Untuk promosinya saya rekomendasikan untuk menggunakan 


\section{Journal of Software Engineering Ampera}

Vol. 1, No. 3, October 2020 e-ISSN: 2775-2488

https://journal-computing.org/index.php/journal-sea/index

website untuk memajang produk-produk bulumatanya, dan menggunakan sosial media seperti instagram, facebook, dan bahkan tiktok karena sekarang apps itu sedang menjadi trend di kalangan anak muda. Lalu untuk di bagian penjualanya menggunakan website yang sudah bisa untuk melakukan jual beli supaya menambah pasar lagi sampai ke luar negeri dan menambah pasar di dalam negeri juga. Untuk di sosial medianya juga perlu dibuat agar menarik, contohnya membuat template yang tidak membosankan.

\section{DAFTAR PUSTAKA}

Hendri Sukatjo, S. R. A. (2010). Analiosa Marketing Mix-7P(Produk, Price, Promotion, Place, partisipant, Process, dan Physical Evidence ) terhadap Keputusan Pembelian Produk Klinik Kecantikan Teta di Surabaya. Jurnal Mytra Ekonomi Dan Manjemen Bisnis, 1(2), 216-228.

Irawan, Y. (2017). PERENCANAAN STRATEGIS SI / TI DENGAN MENGGUNAKAN FRAMEWORK WARD AND PEPPARD DI SEKOLAH TINGGI ILMU KESEHATAN ( STIKes ). Jurnal IImu Komputer, 6(1), 25-32.

Sujana, N. (2017). Perencanaan Strategis Sistem Informasi Dengan Pendekatan Ward and Peppard. Tematik, 4(1), 68-85. https://doi.org/10.38204/tematik.v4i1.173

Nazir, M. (2014). Metode Penelitian. Bogor: Ghalia Indonesia. Ibrahim. 2015. Metode Penelitian Kualitatif. Bandung: Alfabeta.

Adhaghassani, F. S. (2016). Strategi Bauran Pemasaran (Marketing Mix) 7P (Product, Price, Place, Promotion, People, Process, Physical Evidence) di Cherryka Bakery. Jurnal Pendidikan Teknik Boga.

Aisya, F. D. (2016). Strategi Bauran Pemasaran (Marketing Mix) Dalam Industri Rumahan Emping Melinjo di Kecamatan Limpung Kabupaten Batang. Skripsi. Universitas Negeri Semarang. 